\title{
Leveraging Mobile Devices to Develop Intercultural Competency for Digital Students
}

\author{
Matthew Willis and Elaine M. Raybourn \\ Sandia National Laboratories, P.O. Box 5800 MS 1188 \\ Albuquerque, New Mexico USA, 87185 \\ \{mwillis, emraybo\} asandia.gov
}

\begin{abstract}
Mobile devices can help digital students reach out across cultures to develop intercultural competence, improve learning, and provide course support for a variety of course topics. Intercultural competence is expressed through openness, cognitive adaptability, and behavioral flexibility toward unfamiliar cultures. Digital students demonstrate a behavioral flexibility toward technology use that can be leveraged to encourage students to embrace cultures different from their own. This paper explores the feasibility of using mobile devices as viable options for course support by utilizing traditional learning styles and cultural learning styles. From the conducted survey preferred networks are identified for creating a community to support mobile learning.
\end{abstract}

Keywords: mobile device, eLearning, Diffusion of Innovations, mobile learning, online community, intercultural competence, digital students.

\section{Introduction}

\section{"The object of education is to prepare the young to educate themselves throughout their lives." -Robert M. Hutchins}

Modern educational research has investigated the question of how educators may use technology effectively to stimulate and support learning, collaboration, and the educational needs of incoming and future university students. The opportunity of using technology for educational purposes comes with challenges and benefits for both students and faculty. In particular, the use of mobile devices primarily designed for entertainment adds another layer of complexity. We define mobile devices as any portable device that can display audio, video, text, images, or all four information sources. In particular we are concerned with mobile devices that are pocket-sized, that is, not a laptop but a handheld device such as but not limited to the iPod, iPhone, Zune, Nomad, Archos, iRiver, Creative Zen, Blackberry, Sidekick, and most all-inone-phones and personal data assistants. The commonality is that they are all designed to be held in the hand, used on the go, stored in a pocket, and are multifunctional. This study presents current academic research on the advantages and disadvantages for faculty and digitally minded students on mobile learning, 
e-learning, and digital pedagogy [1]. Mobile devices can help digital students reach out across cultures to develop intercultural competence, improve learning, and provide course support for a variety of course topics. Intercultural competence is expressed through openness, cognitive adaptability, and behavioral flexibility toward unfamiliar cultures [2]. Digital students demonstrate a behavioral flexibility toward technology use that can be leveraged to encourage students to embrace cultures different from their own.

The first author conducted a survey of a large minority majority southwestern university in the United States and analyzed the data guided by Diffusion of Innovations theory [3]. A minority majority university is comprised of a student population whose racial composition is less than $50 \%$ non-Hispanic white. The analysis investigated student ownership of mobile devices, past experience with mobile devices, current use of the mobile device, and self-reported learning style preferences. In gathering data on student use of mobile devices questions about social networks were also included since most mobile devices allow an overwhelming majority of college students in the United States use social networking sites and online communities to manage personal and professional relationships [4]. Awareness of existing social networks and knowledge of mobile device use can help universities to develop curriculum, learning support structures, alternative learning methods and save on financial costs in implementing ways for students to learn with the aid of technology. Ideas for how educators can leverage mobile devices to help students develop intercultural competence are also offered throughout our analysis.

\subsection{Mobile Devices in the Classroom}

With computer systems readily available in most homes and throughout most U.S. university campuses, many students are turning to electronic methods of information interaction and consumption. Many students are accustomed to using the internet to pay bills, shop for textbooks or clothes, and look up information for a class homework assignment. The availability of accessible computer systems has crept into the university, where students expect to continue using the technology they have become so accustomed to in their daily life. This expectation presents challenges for both students and faculty. For example availability of technology and experience using technology are now important aspects of not only the student's scholarship but also to be successful in university life and beyond. Demand for technology has created pressures on some faculty that are now challenged to learn, integrate, and evaluate technology for classroom use in addition to other duties [5].

Duke University was one of the first universities to implement the iPod learning initiative for 1,600 incoming freshman [6]. They used the mobile device as a method of coursework support. The findings of the Duke iPod initiative indicate numerous advantages and disadvantages that ultimately suggested further study was needed before implementation. The Duke University model provided iPods along with educational audio attachments to 1600 incoming freshman. Various other universities and institutions have since deployed similar models of supplying mobile devices and training to students and faculty on how to use them [7], [8], [9], [10], [11], [12], [13].

The Duke University iPod initiative project also noted limited training resources and lack of awareness about mobile device functionality as challenges to 
university-wide deployment [6]. However, the Duke University study was first implemented in 2004. By now, knowledge of the idea to use mobile devices for teaching and learning could have diffused through campuses nationwide given the 4year time gap. Also, student and faculty knowledge about mobile device usage has increased significantly since 2004 given that mobile devices continue to be highly popular entertainment devices and their use has diffused rapidly especially among college demographics.

Current research that studies the use of mobile devices as educational tools indicates that mobile devices can be effective solutions for increasing student participation, reinforcing study habits, and grasping course content [8]. However, the beneficial aspects of this technology are also met with realistic problems and criticisms such as the expense of the technology, and student distraction or disconnection due to technological overload [14]. Additionally the use of new media may open the door to various administrative and departmental red tape [10] The spread of technology use in academia has created a need for administrative bodies to oversee, direct, and implement technological learning at universities [7].

Technical literacy is the degree to which someone understands and uses technology such as portable devices, laptops, and desktops. Technical literacy is a common trait among college level students. This digital native [15]skill set is a trend that continues in younger students and persists as they grow up. This phenomenon is commonly called "digital-minded students" as articulated by [1]

"Digital students possess a mentality in tune with the new media, take the availability of email, instant messaging and text messaging for granted, and use unlimited online resources. The digital world has had a significant impact on their cognitive functions. They expect to try things rather then hear about them." ( $p$ 42).

This emerging construct of the digital minded student is impossible to overlook and becoming more and more of a common student profile on the university campus in the United States. Mobile devices can help digital students reach out across cultures to develop intercultural competence. Intercultural competence is expressed through openness, cognitive adaptability, and behavioral flexibility toward unfamiliar cultures [2]. As communication media and mobile devices make it easier for each of us to interact with members of different cultures and contexts, intercultural communication becomes more commonplace in our daily life. Intercultural communication is the exchange of information and the co-creation of meaning between individuals or among groups (teams, organizations, etc) that perceive themselves to be different [16]. Digital students demonstrate a behavioral flexibility toward technology use that can be leveraged to encourage students to embrace cultures and languages different from their own.

Mobile devices have already shown to be a successful supportive device for special needs students and students of English as a second language [12]. Mobile device learning has been most successful when supported by peer assisted learning using a collaborative model in English as a foreign language programs. This model is hypothesized as being highly relevant and critical to use for educational success given the increase in globalization and internationalization in academia, business, 
technology, science, and commerce [17]. Unique opportunities exist for using mobile devices to support situated learning containing activities that have an authentic context and culture, whether it be translation or activities for cultural competence building [18]. Additionally there are numerous reports of academic success when mobile devices are implemented in the university setting as a tool to support or supplement lecture and classroom learning [1], [6], [8], [19]. The key is to implement mobile devices as supportive educational tools, as it has been noted that too great a proliferation of lectures available as digital files would motivate students to miss class or skip lectures because they can just download the discussion [19]. However, Copley found through focus groups and survey analysis that there is no supplement to being present in the classroom, where the majority $(57 \%)$ of students said that podcasting would not reduce their course attendance, $31 \%$ stated that any effect would depend on the lecture course [19]. Major reasons that podcasting would not affect attendance appear to be the need for routine or structured learning, opportunities for interaction/questions, and that a live performance is better than a recorded performance. Technology use in the classroom, regardless of how it is used, presents challenges and opportunities for faculty as well as students. Some faculty may require training in using the technology [13], but the benefits of learning to use such technology can facilitate professional career growth.

Finally, the ability to review a lecture or listen to an audio podcast to help fill in a students notes is not only consistent with establishing learning and study habits outside the classroom, but nourishes healthy habits of lifelong learning [1]. Including and encouraging the use of technology in the multicultural classroom also builds peripheral skills for both educators and students, skills and knowledge in effective technology use, criticism, and literacy that are required by our society to thrive in the 21 st century [5].

\subsection{Research Questions}

Diffusion of Innovations (DI) was selected as a theoretical grounding for the present study. DI was also selected as a grounding principle to investigate mobile device usage in a United States Southwestern university because there are few studies using DI to describe current networks among college students since the diffusion of mobile devices that could potentially help students to develop intercultural competence. One study investigating the use of technology in the classroom guided by DI specifically focused on the adoption patterns of faculty who integrated technology into the classroom [11]. This study was useful to understand faculty technical literacy such as use of word processing, spreadsheets, charting and graphing, databases, presentation software, email, internet, listservs, FTP, and web page creation. The present study investigates technology that was not measured in Jacobsen's 1998 study and seeks to identify student networks of use and knowledge regarding mobile devices.

To direct the data collection for this exploratory study, two research questions were formulated from the synthesis of the literature:

RQ1: Will the percent of mobile device penetration among the surveyed student population be large enough to support the notion that mobile devices can be leveraged for learning? 


\section{RQ2: How can interpersonal, intercultural, and online communities be utilized for diffusing training and course content on mobile devices?}

If mobile devices achieve a critical mass in the student body (as research question 1 asks) then reinventing the devices as course support and learning aids is a viable option. The higher the percentage of mobile device ownership the more likely students will know what one is and how to use it. This addresses the problem of training and knowledge about mobile device use. Research question two is an indictor for developing a support network for using mobile devices as learning tools. By looking at the current use and ownership of social networking sites possible strategies can be drafted for reinventing these already popular sites to aide with the development of implicit and explicit user profiles [16] around course work, topical research, and other university content opinion leaders (influential students in math, biology, social sciences, etc). Additionally previously established social networks can encourage the sharing of ideas and intercultural learning across cultures and disciplines or within disciplines across classrooms. In accordance with Diffusion of Innovations theory, using readily available social networks of interpersonal, intercultural, and online friend sites can prove beneficial for universities considering mobile device use for coursework support.

Questions were also asked on the survey concerning the students' self-report of learning styles, and whether those learning styles compliment the use of a mobile device. Assessing and accessing the learning styles of current mobile device users may reveal another support mechanism for educational use. Mobile devices may be a popular option if the majority of students have a learning style (namely visual, auditory, and kinesthetic) that is compatible with the use of a mobile device.

\section{Method}

Data were gathered through the use of a voluntary internet survey designed and hosted on the service surveymonkey.com. An online survey design was selected for two important reasons. First, ability to access the Internet implies some level of digital availability as well as some degree of technical literacy skills. Second, an internet survey can easily be passed through departmental email list services to ensure a diverse convenient sample of students across disciplines and year of scholarship.

Survey respondents were solicited from the following academic departments: Art \& Art History, Earth \& Planetary Sciences, Theater \& Dance, Psychology, Architecture \& Planning, Biology, and the University Honors Program. Once departmental listserv access was obtained, identical emails were sent to each listserv requesting anonymous participation for the survey.

The survey was designed using Diffusion of Innovations theory as a guiding framework. The diffusion process is defined as (1) an innovation that is (2) communicated through certain channels (3) over time (4) among the members of a social system [3]. For this study the innovation is both the mobile device and knowledge about using a mobile device that comes with technical literate students. Concerning research question two the communication channels identified are both the student's interpersonal friendships they maintain in their scholarly and personal life, the other communication channel is any mass media online friend networks such as 
MySpace and Facebook that student is a member of. These two channels of both interpersonal and online friend networks serve as a means by which messages get from one individual to another.

\section{Results and Analysis}

Results indicated that there are $86 \%$ (218 students) of the total surveyed population $(\mathrm{N}=275)$ that own some brand of mobile device, while $13 \%$ (35 students) currently own no mobile device. A total of 253 students answered this question. Research question one is supported in this finding; the amount of ownership suggests that the mobile device has enough visibility in student use that the concept of using these devices as a course support tool becomes practical.

Of all the students surveyed $62 \%$ identified as White (European, Eastern European, Caucasian) $20 \%$ identified as Hispanic or Latino, $6 \%$ identify as Multi-Racial, $4 \%$ as Native American, $3 \%$ as Asian, $1 \%$ as Non-Hispanic, $1 \%$ as Black, and $0.7 \%$ as Pacific Islander. It is important to note the representation of diversity in this sample, both in the breadth of departmental sampling and cultural diversity. The diversity at this university means that students are more likely to encounter intercultural situations in every class regardless of educational department.

Looking at what interpersonal network students used to acquire a mobile device, $32 \%$ used a friend's mobile device, $25 \%$ bought a mobile device without trying it, and $12 \%$ used a family member's. Students use mobile devices primarily for music at $91 \%$. This finding idicates that mobile devices are indeed used for entertainment. The primary reason for this is explained by the advertising model for mobile devices as able to play music. This is further enforced by most mobile devices having an online store or online music repository that users can access to download music. Qualitative feedback from participant comments suggested that most students use their mobile device functionality to listen to music while they study or read, but do not listen to audio books or lecture notes on the device. Few students had downloaded a lecture or used their mobile device to study or consume educational course content.

When recipients were asked what online communities they were involved with and had the ability to check all that apply: $49 \%$ used Facebook, 46\% used MySpace, 16\% were active in an online forum, $11 \%$ had a blog, $6 \%$ are members in an online game community, and $23 \%$ of respondents were involved with absolutely no online communities or social networks (multiple answers allowed). Research question two is supported by this identification of popular and widely used social networks. These networks not only expose students to intercultural communication events that occur from the social networks broadening of the users interpersonal network, but social networks may also be used to promote the use and sharing of classroom content. Shared content on these social networks may consist of lectures, audio notes, quizzes, mental exercises, and other educational content that can be used on media devices. Social networks, by their very design, suggest that the students using them are creating content and interacting with content on these social networks. Given the proper tools and structure, students could also create educational content and useful coursework support content on these networks, adding further value to the educational reinvention of media devices. 
The biggest year of growth for mobile device adoption was from 2005 to 2006, where approximately $35 \%$ of surveyed participants purchased their first mobile device. This occurred shortly after the Duke University study in which mobile device adoption was a problem, as too few students owned them and fewer knew how to use them.

The three dominant self-reported learning styles were: visual $(28 \%)$, kinesthetic $(25 \%)$, and auditory (13\%). It is suggested that by targeting learning styles this may be a successful way to further facilitate effective learning in and out of the classroom with mobile devices. Of the students surveyed $18 \%$ used a mobile device to understand and study course material while $74 \%$ did not. $51 \%$ of students showed interest in the opportunity to use a mobile device for course support (even if they did not own one). Lastly, $11 \%$ of respondents have used the iTunes online store to download digital content such as lectures, talks, discussions, and presentations from other universities, while $88 \%$ had no experience engaging in this activity. The iTunes University was surveyed because it is a useful model to look at in the design and dissemination of course support content, such as MIT's open courseware hosted on iTunes University.

\section{Discussion}

It has been shown that enough students in the university have access to a mobile device to gain benefits from any course support system that would require mobile device use. Additionally, the student population surveyed was such that the likelihood of encountering intercultural communication opportunities was great. A high diffusion level such as the one reported in this survey may be the first step in overcoming previous reported barriers such as limited training resources and lack of awareness and accurate knowledge of mobile device functionality (Belanger, 2005), since a high rate of adoption means that individuals can gain knowledge about the device from the users around them. The $35 \%$ increase from 2005 to 2006 supports the idea that mobile device ownership has become more common on college campuses and indeed continues to increase. Mobile devices that facilitate interpersonal communication and access to online communities may be leveraged to help students interact more in intercultural settings, thus enhancing their opportunities to develop intercultural competence. As suggested by previous research, and as evidenced by the minority majority university this study was conducted at, students are increasingly likely to encounter situations in both business and academia where intercultural skills are needed. To build upon previous studies, utilizing learning styles and online communities can continue to bolster the intercultural communication efficacy and understanding of students. Mobile devices that support video and pictures would make it a complimentary tool for use with preferred visual learners; devices with audio capabilities also make these devices a strong choice for auditory learners. This can be coupled with peer assisted (in the classroom) collaborative learning environments to maximize cultural and contextual learning [18].

Because a mobile device clearly compliments visual and auditory learning methods, the ability to use a portable device while a person does other kinesthetic tasks such as working on a hands on project and listening to a lecture, or working out 
and listening to course content may be a way that a mobile device can support kinesthetic learners as well. It allows the student bodily movement while they are studying relevant intellectual content.

It is important to note the significance that culture plays in the learning process. Mobile devices are capable of supporting important cultural learning frameworks students may be accustomed to, such as growing up in an oral culture or written culture. Oral and written cultural identities effect the way a student processes information, giving students an option to interact with information that may also compliment their cultural background [20] is an opportunity to encourage the development of intercultural learning communities and also bridge cultural differences with educational technologies.

Mobile devices provide a unique opportunity to engage digital students through a medium they are familiar with. These devices also provide a unique opportunity to support cultural learning and foster intercultural communication through coursework support via sharing and social networks. Further research is needed to understand the benefits of using a mobile device to support learning styles. Also, future research should investigate student retention of information presented to them using mobile devices. The findings from this study suggest support and relevance for reinventing the mobile device as an educational tool. Benefits from using a mobile device educational model include accessing students preferred learning styles for effective learning, improved comprehension, encouraging the building of intercultural and interdisciplinary networks, and student educational involvement.

\section{Limitations of the Research}

One limitation of this research is that it was an exploratory study and can only provide frequencies concerning mobile device use, learning preference, and knowledge. Further research is needed to investigate relationships of mobile device use to build inferential statistical models to better explain the phenomenon, benefits, and consequences of mobile learning. Also, future research should measure cultural learning and use of mobile devices to further investigate the relationship between intercultural communication and use of educational mobile devices. This study has found that mobile devices have permeated universities and created certain communication channels and networks that the generation of "digital students" are now a part of. The study also found that while many students use a mobile device, few use media devices for learning and course support; they are primarily considered entertainment devices. Using online communities is important for diffusing additional course support that can benefit students learning styles and intercultural communication abilities. Further investigation into these existing networks and learning styles could unlock possibilities for new and innovative pedagogical experiences as well as helping universities cultivate future generations of insightful, curious, critical, intelligent students and world citizens.

Acknowledgments. Sandia is a multiprogram laboratory operated by Sandia Corporation, a Lockheed Martin Company, for the United States Department of Energy under Contract DE-AC04-94AL85000. 


\section{References}

1. Andone, D., Dron, J., Pemberton, L., Boyne, C.: E-Learning Environments for Digitallyminded Students. Interactive Learning 18, 41-53 (2007)

2. Raybourn, E.M.: Designing an Emergent Culture of Negotiation in Collaborative Virtual Communities: The Dome City MOO Simulation. In: Churchill, D.S., Munro, A. (eds.) Collaborative Virtual Environments. Springer, Heidelberg (2001)

3. Rogers, E.M.: Diffusion of Innovations. Free Press, New York (2003)

4. Social networking statistics. Nielsen audience analysis, New York (2007)

5. Serim, F., Schrock, K.: Nailing Digital Jelly to a Virtual Tree. Learning \& Leading with Technology, 12-16 (December/January 07-08, 2007)

6. Belanger, Y.: Duke university Ipod First Year Experience Final Evaluation Report (2005)

7. Albright, M.J., Nworie, J.: Rethinking Academic Technology Leadership. Educause Quarterly 1, 12-23 (2008)

8. Blaisdell, M.: Academic MP3s: Is it Time Yet? (2006)

9. Gatewood, K.: Podcasting: Just the Basics. In: Kappa Delta Pi Winter 2008, pp. 90-93 (2008)

10. Gillard, S., Bailey, D.: Technology in the Classroom: Overcoming Obstacles, Reaping Rewards. The International Journal of Learning 14, 87-93 (2007)

11. Jacobsen, D.M.: Adoption Patterns of Faculty Who Integrate Computer Technology for Teaching and Learning in Higher Education. In: ED-MEDIA AND ED-TELECOM 1998: World Conference on Educational Multimedia and Hypermedia \& World Conference on Educational Telecommunications, Freiburg, Germany (1998)

12. Millard, E.: Learning with Personal Media Players. District Adiminstration, 61-64 (May 2007)

13. Reardon, R.M.: Learning What I Don't Know How to Do. Educause Quarterly 1, 4-5 (2008)

14. Bugeja, M.: The Age of Distraction: The Professor ot the Processor? The Futurist, 66-68 (2008)

15. Small, G., Vorgan, G.: iBrain: Surviving The Technological Alteration of The Modern Mind. Collins Living, New York (2008)

16. Raybourn, E.M., Kings, N., Davies, J.: Adding Cultural Signposts in Adaptive Community-Based Virtual Environments. Interacting with Computers 15, 91-107 (2003)

17. Lan, Y.-J., Sung, Y.-T., Chang, K.-E.: A Mobile-Device-Supported Peer-Assisted learning System For Collaborative Early English as a Foreign Language Reading. Language Learning \& Technology 11, 130-151 (2007)

18. Naismith, L., Lonsdale, P., Vavoula, G., Sharples, M.: Mobile Technologies and Learning. Futurelab, 1-48 (2004)

19. Copley, J.: Audio and Video Podcasts of Lectures for Campus-Based Students: Production and Evaluation of Student Use. Innovations in Education and Teaching International 44, 387-399 (2007)

20. December, J.: Characteristics of Oral Culture in Discourse on the net. In: Twelfth Annual penn State Conference on Rhetoric and Composition, University Park, Pennsylvania (1993) 